\title{
ANALYSIS OF OPERATION OF ARCH FRICTIONAL JOINT LOADED WITH THE IMPACT OF FREELY FALLING MASS
}

\author{
JAROSŁAW BRODNY \\ Institute of Mining Mechanization, Silesian University of Technology, Gliwice, Poland. \\ E-mail: jaroslaw.brodny@polsl.pl
}

\begin{abstract}
Yielding support, commonly applied to secure dog headings, is made of carrying elements in the form of steel frames and friction props. Yielding capacity of this support is realized in frictional joints, which due to their geometry can be divided to straight and arch joints. Occurring in steel frames arch frictional joints are characterized with more complex loading state than straight joints used in friction props. In the article, there is presented an analysis of the state of stress and deformation of the arch frictional joint, which was carried out on the model of these joints using finite element method. The scope of the analysis included two methods of loading of arch frictional joint, namely its axial compression and bending. In both cases, joints were loaded dynamically with the impact of freely falling mass. Arch joints with and without passive pressure were submitted to an axial compression. Physical model of the frictional joint was developed on the basis of a system applied during the stand tests. To solve mathematical model an explicit integration method was used. As a result of analyses carried out, temporal courses of force transmitted through the frictional joint, and displacements of section sliding down were determined. On the basis of the temporal courses, dependences between maximum value of force transmitted through the frictional joint and the height from which the impact mass falls down were determined. Distributions of reduced stresses in elements of frictional joint were also determined and the state of deformation was described. In order to emphasize the difference between straight and arch frictional joints, also an analysis of internal forces in arch frictional joint depending on its geometrical parameters without and with passive pressure was presented.
\end{abstract}

\section{INTRODUCTION}

In yielding support of dog headings, there are two types of frictional joints, namely: straight and arched. The base for this division is the radius of curvature of sections forming the frictional joint. In the case when the joint is made of rectilinear sections of the profile, we are dealing with a straight joint, which is used mainly in the friction props. In steel frames of yielding support we deal with an arch frictional joint, in which contact between the cooperating sections takes place along an arc line.

Despite the widespread use of arch frictional joints, studies which concern research and analyses of their operation are rarely met. Practically, besides papers [1], [4] there are no elaborations concerning arch frictional joint studies.

It seems that the cause of that are problems resulting from their geometry, which has influence on more complex distribution of internal forces in relation to a straight joint. This makes it difficult to carry out research of these joints, due to the necessity of having a specialized test stand, which is related to high cost of these studies. 
Stand and underground tests, despite many advantages have also other limitations regarding mainly range of changes in parameters describing the frictional joint and the way of its loading. These tests unable also determination of distributions of stresses and deformations of particular elements of frictional joint during its operation.

The possibilities of such an analysis are created by model studies carried out on the structural model of frictional joint, and in some range could be an alternative and complement to stand tests and tests in real conditions.

Such a way of modeling was used in developing an arch frictional joint model in order to carry out simulation studies on this model, loaded with an impact of freely falling mass.

The fundamental source of information, necessary for the development of physical and mathematical models of arch frictional joint, were stand tests of joints loaded with an impact of freely falling mass [2].

A mathematical model of continuous medium, which is a frictional joint after spatial discretization using the finite element method, is an initial-value problem described by a system of ordinary differential equations with the appropriate initial conditions.

The equations of motion are determined based on second order Lagrange's equation, indirectly derived from the second law of Newton's dynamics. General equation of motion describing the mechanical system in matrix form is [6], [7]

$$
M \cdot \ddot{y}+C \cdot \dot{y}+K \cdot y=P(t)
$$

where

$M$ - matrix of inertia,

$C$ - damping matrix,

$K$ - rigidity matrix,

$P(t)$ - generalized forces vector,

$\ddot{y}-$ generalized accelerations vector,

$\dot{y}-$ generalized velocity vector,

$y$ - generalized displacements vector.

Equation (1) is the matrix form of ordinary differential equations, linear with constant coefficient. In the present paper, to solve these equations an explicit integration method was used [3], [6], [8].

This method consists in the fact that an equation of the motion is integrated over step by step, which means that it has to be satisfied only at the selected moments, and not in the entire range of integration. A relatively short time of determining the following unknown values at subsequent moments of time is an advantage of the explicit integration method. Application of the mass matrix diagonalization caused that there is no necessity to invert the matrix in order to solve the system of algebraic equations. The calculation time depends only on the number of the model's degrees of freedom. The disadvantage of this method is the necessity to apply a short time step the integration, because too long a time step causes occurrence of numerical instabilities. 
Taking into account the specificity of operation of arch frictional joint, and difficulties with its stand and underground tests, in the present paper an analysis of operation of this joint, using the finite element method was performed [3], [8]. This analysis included the case of dynamic loading of a joint resulting from the action of freely falling impact mass.

Studies presented in this paper included two cases of loading of arch frictional joint, namely its axial compression and bending.

\section{PERFORMANCE CHARACTERISTIC OF ARCH FRICTIONAL JOINT}

The specificity of an arch frictional joint operation with respect to straight joint results from its different geometry, which has significant impact on the distribution of internal forces in this joint. Besides longitudinal compressive force, which predominates in straight joints, there are also shearing force and bending moment [1].

The difference between those joints within the internal and external passive forces (of the reaction) is particularly visible in the case of their axial compression. In the case of a straight joint one can assume that during the axial compression of the cooperating sections, an axial force acts, causing their compression. A geometric shift of the centre of cross-section between the cooperating sections causes that the bending moment and shearing force occur. However, their values are small, and the influence on the state of deformation and stress is negligible; in consequence, their influence is not taken into account during the calculations of straight frictional joint.

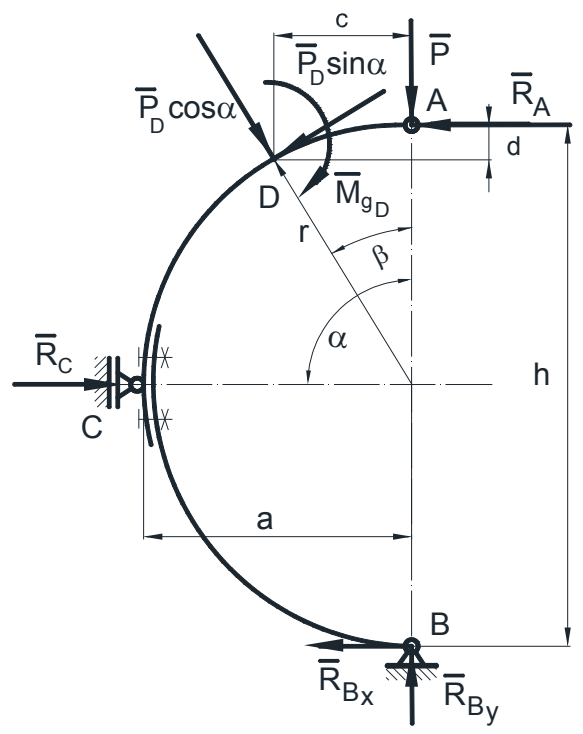

Fig. 1. Scheme of the loading with a distribution of internal forces in the cross-section of arch frictional joint with passive pressure 
For an arch frictional joint axially loaded (along the straight line connecting its ends) the influence of bending moment and shearing force is very relevant.

Figure 1 presents the distribution of internal forces in arch frictional joint crosssection at point $\mathrm{D}$, loaded with an external force $P$. The joint is attached at the ends and is also supported in the center of the arch at point $\mathrm{C}$. Reaction $R$, occurring at this point, is called a passive pressure.

The complex loaded state of particular cross-section of arch frictional joint has a significant influence on the nature of its work, deciding together with the values of friction forces between cooperating sections, whether a yield in a joint will occur, or it will be working as rigid. A very significant impact on the values of the internal forces is also due to the way of supporting the joint, which should reflect the rock mass interaction to the steel frames. This regards particularly taking into account the side thrust, which impacts the arch joint. In practice, this side thrust could be a passive force (reaction) or an active force resulting from the rock mass interaction on the steel frames, and it is dependent on the way the steel frames are assembled in dog heading and on rigidity of liner [5].

A very significant impact on the distribution of internal forces and the values of reaction is also exerted by a geometry of the arch frictional joint.

Using the scheme adopted (Fig. 1) one can determine an impact of the chord of arch $(h)$ and the rise of arch $(a)$ on the value of the bending moment and transverse and longitudinal forces operating in the cross-section of the arch.

An equation of bending moment acting at point $\mathrm{D}$ of the cross-section of the arch has the form

$$
M_{g \beta}=-P \cdot c+R_{A} \cdot d,
$$

whereas the angle $\beta$ varies in the range: $0 \leq \beta \leq \alpha$.

Using the geometrical dependences one can determine

$$
\begin{gathered}
\sin (\alpha-\beta)=\frac{0.5 h-d}{r} \Rightarrow \cdot d=-r \sin (\alpha-\beta)+\frac{h}{2}, \\
\cos (\alpha-\beta)=\frac{r-(a-c)}{r} \Rightarrow c=r[\cos (\alpha-\beta)-1]+a .
\end{gathered}
$$

Substituting equations (3) and (4) to equation (2) we obtain

$$
M_{g \beta}=-P \cdot\{r[\cos (\alpha-\beta)-1]+a\}+R_{A} \cdot\left[-r \sin (\alpha-\beta)+\frac{h}{2}\right] .
$$

From this equation we can determine the value of the bending moment acting in an arbitrary cross-section of the arch.

Using equation (5) we can determine the maximum value of the bending moment acting on the arch considered. This value will be reached at point $\mathrm{C}(\alpha=\beta)$ and will amount 
- for

$$
\begin{gathered}
M_{g \beta \max }=-P \cdot\{r[\cos (\alpha-\beta)-1]+a\}+R_{A} \cdot\left[-r \sin (\alpha-\beta)+\frac{h}{2}\right] \\
\Rightarrow M_{g \beta \max }=-P \cdot a+R_{A} \cdot \frac{h}{2} .
\end{gathered}
$$

On the basis of dependences derived above, one can conclude that besides the value of external force, it is the length of the chord of arch $(h)$ and the rise of arch $(a)$ that have a very significant impact on the value of the bending moment acting on the arch frictional joint.

Assuming that there are two main parameters which characterize the geometry of the arch, and that the radii of both sections forming the arch are the same, one can define a geometric coefficient of the arch frictional joint in the form

$$
k_{t}=\frac{a}{h}
$$

When the rise of arch $(a)$ equals zero, we have the case of a simple frictional joint $\left(k_{t}=0\right)$, and when the rise of arch equals half-value of the chord of arch $\left(k_{t}=0.5\right)$, then we take into consideration an arch in the form of a semicircle (Fig. 1).

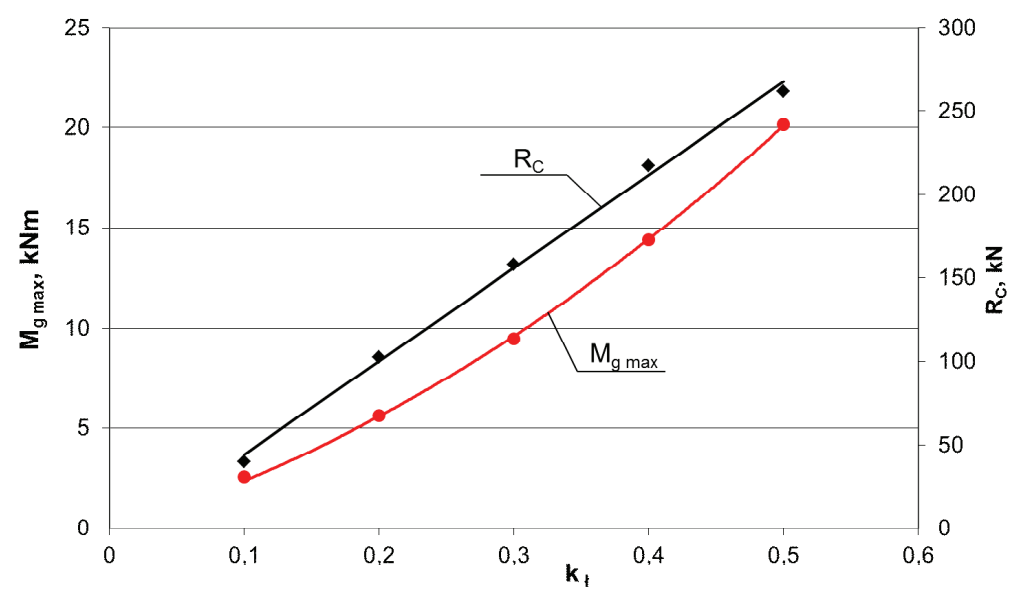

Fig. 2. Influence of the value of coefficient $k_{t}$ on the maximum value of the bending moment $\left(M_{g} \max \right)$ and the value of the reaction under passive pressure $\left(R_{C}\right)$ for a friction joint with passive pressure

In order to determine the influence of passive pressure on distributions and maximum values of bending moment and transverse force operating on arch frictional joint, the calculations for arch frictional joints with and without passive pressure were performed. For each of these cases the active loading was constant and 
amounted to $100 \mathrm{kN}$. The length of the arch chord was also constant and amounted to $1 \mathrm{~m}$.

In the case of calculations of arch frictional joint with passive pressure, there were determined dependences between the geometric coefficient of the arch frictional joint and the maximum value of the bending moment, and the value of reaction (value of passive pressure) operating at point $\mathrm{C}$ in an arch frictional joint with passive pressure (Fig. 2).

Based on the results obtained one can conclude that together with increasing values of geometric coefficient of the arch frictional joint, maximum bending moment and reaction in a passive pressure in arch joint increase.

It is of vital importance for the operation of frictional joint, because the higher the value of bending moment, the more difficult yield occurs in arch frictional joint, and its bending occurs easier.

In analysing arch frictional joint without passive pressure, the values of bending moment being determined are very high, which considerably limits the possibilities of yield occurring within the arch frictional joint.

Also distribution of the transverse force indicates greater possibility of bending process occurring than a yield within joint [1].

\section{AXIAL COMPRESSION OF ARCH FRICTIONAL JOINT}

A discrete spatial model of joint was developed in order to analyze the operation of arch frictional joint subjected to the axial compression with the force arising from an impact of freely falling mass along the straight line connecting the arch's ends. The base to formulate the model was arch frictional joint made of V29 sections with two SDO29 stirrups. The model of the joint consisted of 14 independent solid elements, for which 36 potential contact surfaces were defined. For the materials from which the joints are made, elastic-plastic characteristics were assumed. The joint model with an impact mass is presented in Fig. 3. In this model, it was assumed that initial value of axial force in each of the bolts of stirrups amounted to $80 \mathrm{kN}$.

Two arch frictional joints with different supporting ways were subjected to analysis. In the first case, the joint was without passive pressure, in the second case with a rigid passive pressure. In both cases, the joint was loaded by the impact of the mass of $1000 \mathrm{~kg}$ in perfectly spherical rigid form. Traverse was modeled in the form of an ideal rigid plate of mass $1500 \mathrm{~kg}$.

So modeled arch frictional joint was subjected to numerical analysis, and in result of this analysis there were determined the time course of the force loading joint and distributions of constituents stress state, and deformations of particular elements of joints during its testing. 


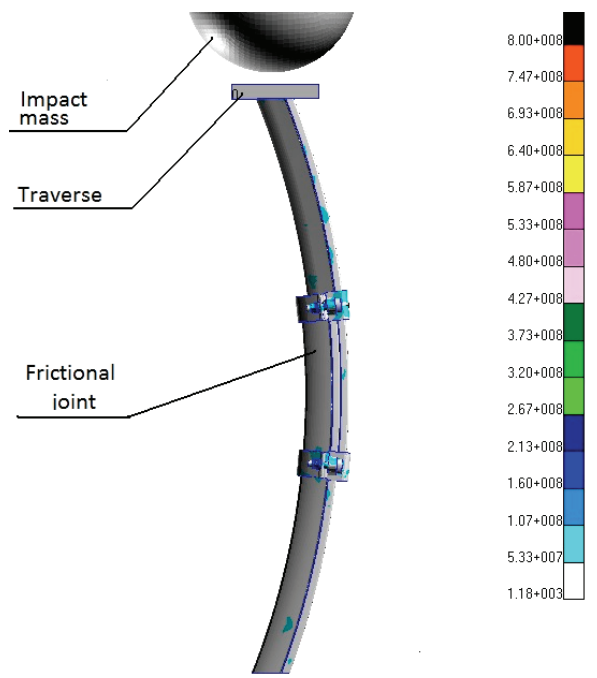

Fig. 3. Discrete model of the arch frictional joint and the way of its loading with an impact of the mass

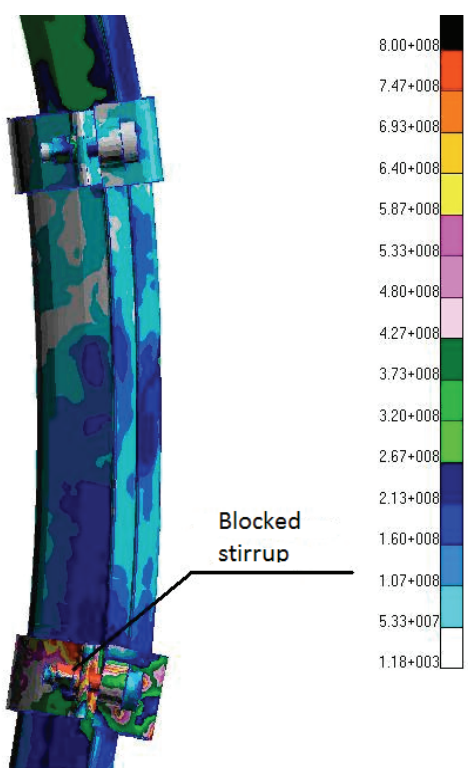

Fig. 4. State of stress and deformation of an arch frictional joint at the moment of its locking

In Fig. 4, there is presented the state of stress and deformation of an arch frictional joint at the moment of its locking. The joint was loaded with an impact of freely falling mass of impact energy amounting to $9.81 \mathrm{~kJ}$. 
During this test, a yield of $0.26 \mathrm{~m}$ occurred in the joint, and maximum value of the force transmitted through the joint amounted to $435 \mathrm{kN}$ (at the moment of its locking).

Analyzing stress and deformation distributions of joint elements in particular phases, one can observe their changes depending on the magnitude of yield. Particularly visible is an increase in the value of stresses in the bottom stirrup of the joint. In this phase of yield the locking of lower stirrup occurred, which reveals as particularly apparent deformation and an increase of stresses in its bolts. Farther yield within the joint causes its unlocking, as shown in Fig. 4.

Tests were performed for the joints with different initial axial forces in bolts of stirrups. In a Figure 5 there is presented state of joint's stress and deformation, for which the values of initial axial forces in each of bolts of stirrups amounted to $100 \mathrm{kN}$.

a)

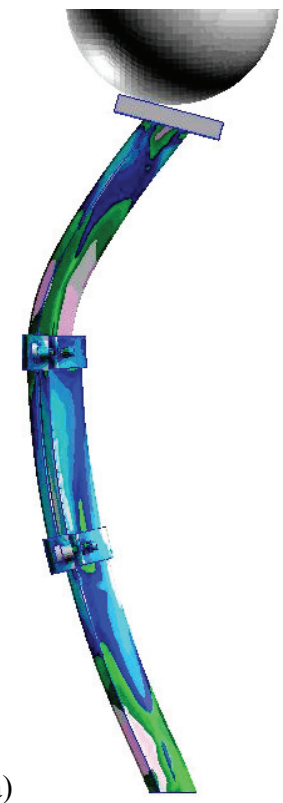

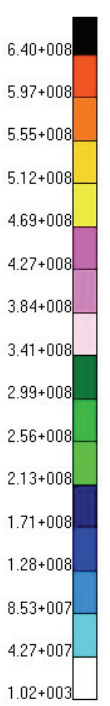

b)

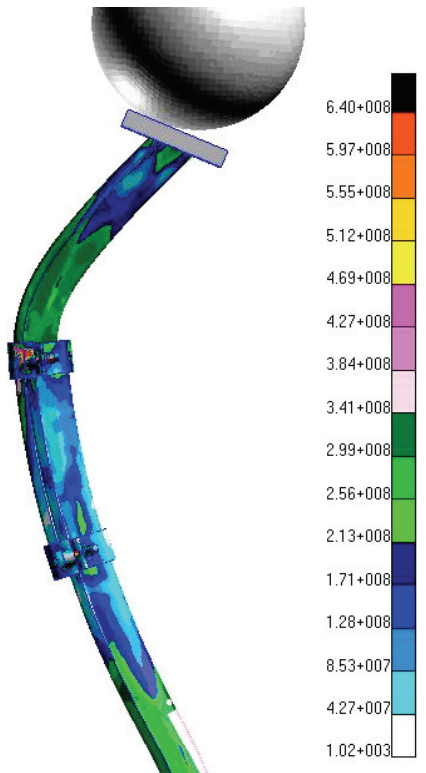

Fig. 5. State of stress and deformation of arch frictional joint without passive pressure, for which the initial value of axial forces in bolts of stirrups amounts to $100 \mathrm{kN}$ in each subsequent phase of its operation

Analyzing the distributions obtained one can conclude that at higher initial axial forces in the bolts of stirrups, yield had not occurred in the joint. The high value of the force, with which the cooperating sections were pressed, caused that instead of yield, before the beginning of an overlap, the bending of upper section occurred. This caused a significant increase of the value of the axial forces in bolts of upper stirrup.

The second system subjected to analysis in the range of the axial compression of arch frictional joint was the joint with rigid passive pressure. 
Figure 6 shows initial and terminal states of stress and deformation in arch frictional joint with passive pressure, for which the initial axial forces in the bolts of stirrups amounted to $100 \mathrm{kN}$ each. The initial state is determined at the moment of contact of an impact mass with a joint, which causes the loading of the upper section (Fig. 6(a)). Terminal phase determines the end of yield within the joint (Fig. 6(b)).

a)

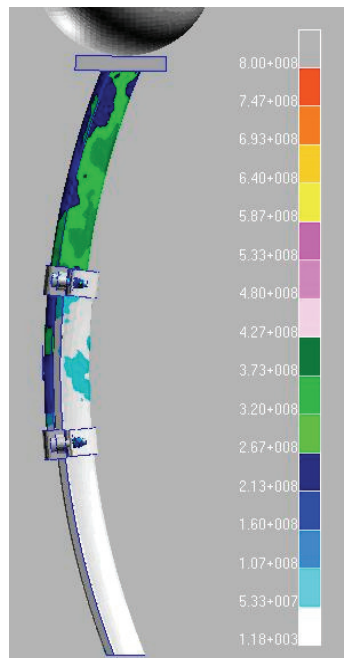

b)

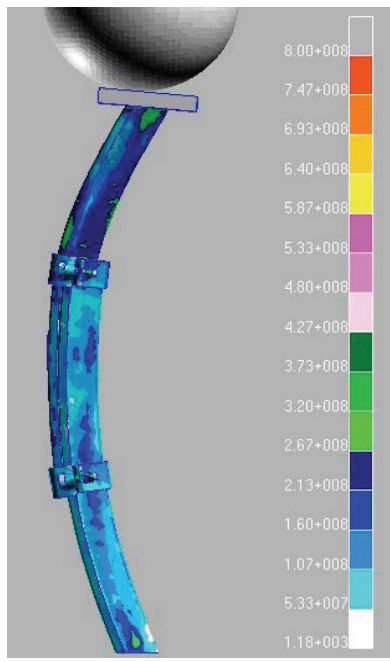

Fig. 6. The initial and terminal state of stress and deformations in arch frictional joint with passive pressure for which the initial value of axial forces in each of the bolts of stirrups amount to $100 \mathrm{kN}$ each

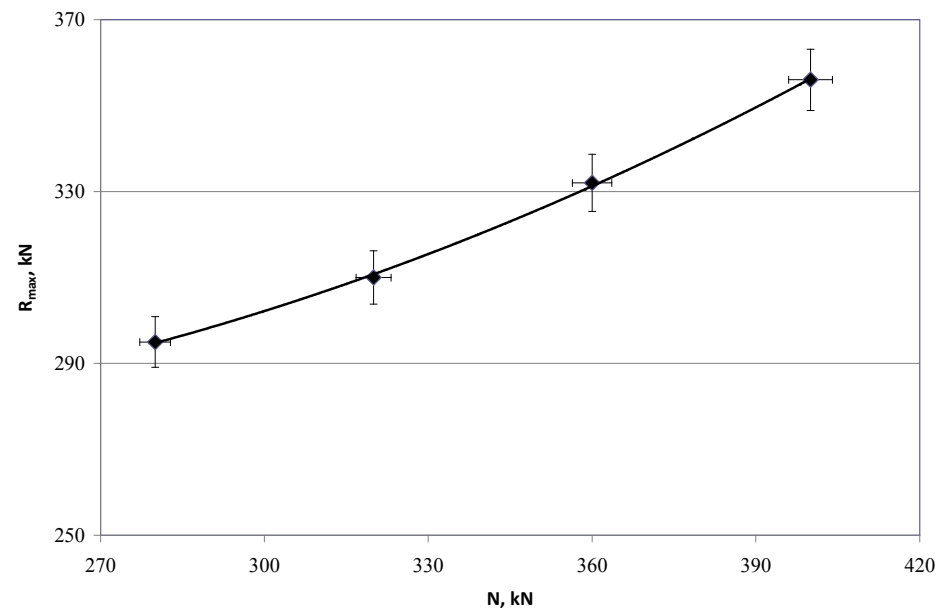

Fig. 7. Dependence between maximum value of force transmitted through the arch frictional joint with a rigid passive pressure and total value of initial axial forces in the bolts of stirrups at constant impact energy 
On the basis of operation characteristics obtained, there was determined a dependence between the maximum value of force transmitted through the arch frictional joint with a rigid passive pressure (maximum load capacity of a joint) and total value of initial axial forces in the bolts of stirrups at constant impact energy (Fig. 7).

Based on the results obtained, one can state that with an increase of total value of initial axial forces in the bolts of stirrups, an increase of loading capacity of arch frictional joint takes place. The presence of passive pressure causes that yield occurs in a joint at high value of initial axial forces in the bolts of stirrups, which in the case of lack of pressure is impossible.

Comparing the operation of an arch frictional joint with and without the rigid passive pressure, one can conclude that the passive pressure caused the occurrence of a yield within the joint. For the same parameters in the joint without passive pressure, a yield did not occur, whereas in the joint with passive pressure, a yield of $0.22 \mathrm{~m}$ occurred. The maximum value of the force transmitted through this joint amounted to $320 \mathrm{kN}$, at the impact energy equal to $9.81 \mathrm{~kJ}$.

\section{BENDING OF ARCH FRICTIONAL JOINT}

The second way of loading the arch frictional joint, which was subjected to analysis, was its bending with the freely falling impact mass. Submitted to the test was the same model of a joint that was used for an axial compression.

A discrete model of arch frictional joint together with the loading system is shown in Fig. 8. In this model, the values of initial axial forces in the bolts of stirrups equal $80 \mathrm{kN}$ in each of the bolts.

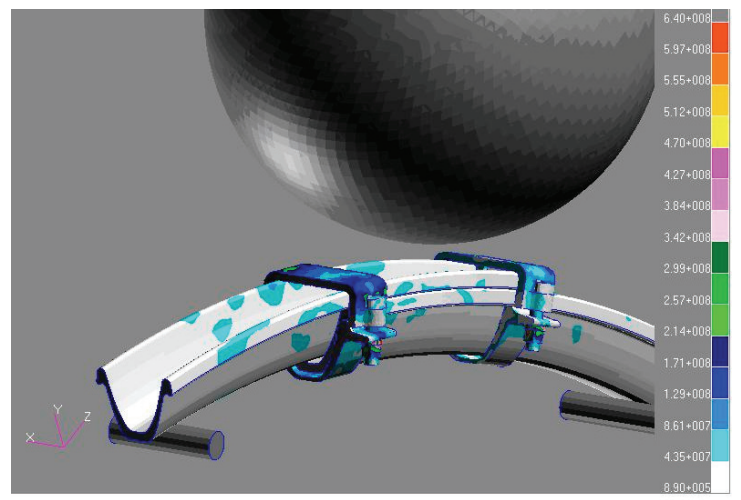

Fig. 8. The discrete model of arch frictional joint during the bending

As a result of analysis carried out, there were determined the states of stress and deformation of joint elements in particular phases of its loading (Fig. 9). 
a)

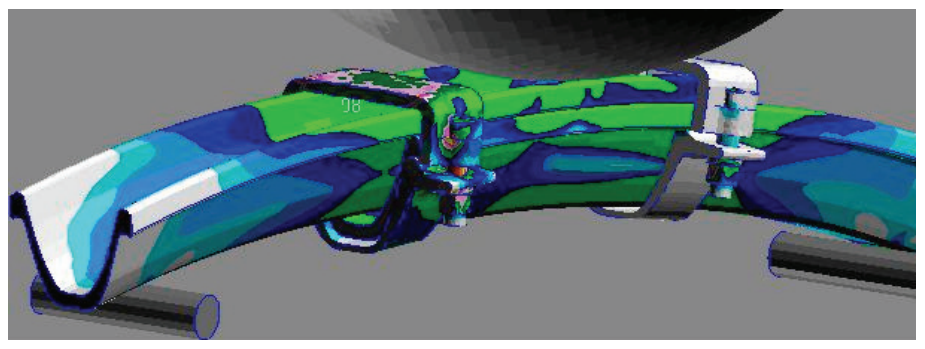

b)

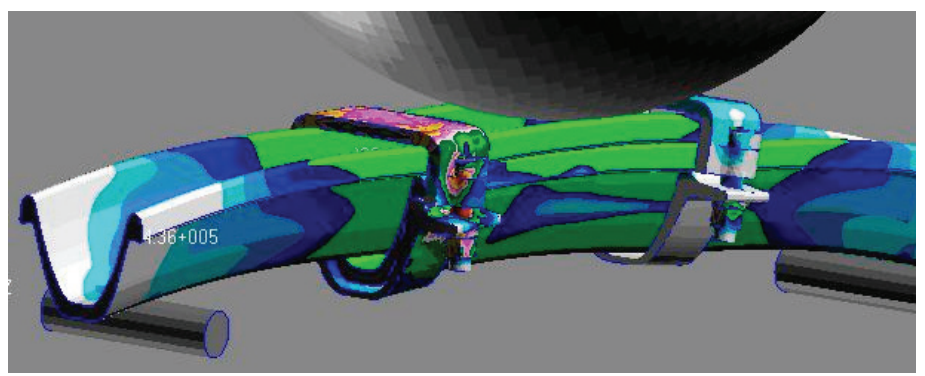

c)

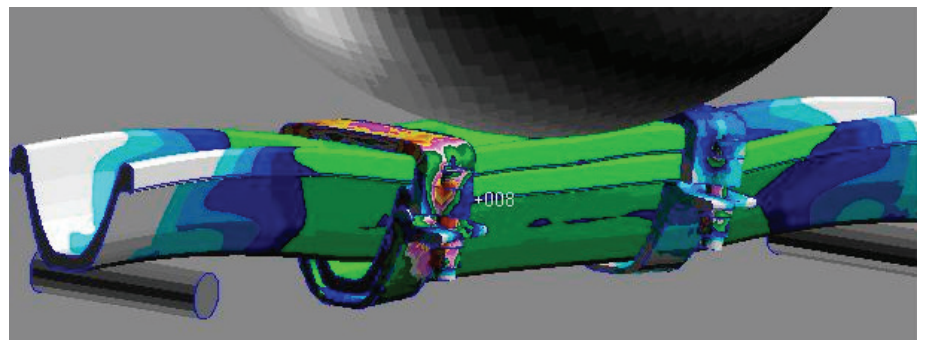

Fig. 9. State of stress and deformation of arch frictional joint elements in subsequent phases of its operation during the bending

Analyzing the distributions obtained, one can conclude that despite the loading of the joint with an ideal rigid impact mass in spherical form, the state of stress of particular joint elements is not symmetrical. This mainly applies to the stirrups. The stress state of lower stirrup is much more disadvantageous than that of the upper stirrup. These differences are particularly apparent in the terminal phase of the bending (Fig. 9(c)) in which bolts of lower stirrup indicate a high state of effort. Bending process includes in principle the cooperating sections at points where an overlap ends and has a similar course as in the case of stand tests [2]. Deformation of cooperating sections in the joint, in place where an overlap ends, limits the possibilities of the yield occurring in these joints. For this reason, in the cases analyzed, very small (several millimeters) yields in joints were recorded. 


\section{SUMMARY AND CONCLUSIONS}

The results of tests presented in the article clearly indicate that the geometry and the way of supporting the frictional joint have a very significant influence on the value of internal forces and components of the state of stress and deformation in particular elements of frictional joint.

Arch frictional joints subjected to the analysis, due to their geometry are characterized by complex loading state, in which the bending moment plays a very significant role. Depending on the geometric parameters of the arch frictional joints, the way of its supporting and loading, the value of the bending moment can decide whether in arch frictional joint a yield will occur, or it will be working as a rigid system.

Application of FEM for the analysis of operation of arch frictional joint enabled us to determine the distributions of state of stress and deformation in its particular elements during an arbitrary instant of loading.

Thanks to that, the state of an effort of these elements could be observed, and their weakest position could be found. It is impossible to perform such an analysis on the basis of stand or underground tests. The results obtained should be used in design works on the improvement and development of new solutions of frictional joints.

The results clearly indicate that the most strenuous of the arch frictional elements are the bolts of stirrups. Both at the axial compression and bending of arch frictional joints, bolts are subjected to very disadvantageous loading, which results in the occurrence of complex state of stress in their cross-section. Additionally, there should also be taken into account the fact of non-uniform loading of stirrups, which was recorded in both cases of loading of arch frictional joints.

During the axial compression of arch frictional joint definitely the bottom of stirrup is more loaded and during bending, the upper stirrup. In each of these cases permanent deformations of bolts of these stirrups were recorded.

The analyses carried out confirm also a significant influence of a liner on the operation of arch frictional joints. A liner in the form of passive pressure, which was simulated in the model developed, had a very significant impact on the occurrence or lack of the yield within the joint. Assuming that the fundamental advantage of yielding support of dog headings is its yielding capacity, in the context of the results obtained, a well-done liner could have a decisive impact on the correct operation of support.

Taking into account the fact of frequent dynamic interaction of rock mass to the yielding support, and tasks which support has to fulfill in dog headings, the use of numerical methods for analysis of its operation is justified.

Summing up, one can conclude that numerical tests should be complement, and in some cases an alternative in relation to stand and underground tests of the elements of yielding support of dog headings. 


\section{REFERENCES}

[1] Brodny J., Analiza obciqżenia łukowego złacza ciernego, Mechanizacja i Automatyzacja Górnictwa, Czasopismo Naukowo-Techniczne, 12(490), 2011, 13-19.

[2] BRoDnY J., Tests of friction joints in mining yielding supports under dynamic load, Archives of Mining Sciences, Vol. 56, No. 2, 2011.

[3] Crisfield M.A., Non-Linear Finite Element Analysis of Solids and Structures, John Wiley \& Sons, 1998.

[4] PYтLIK A., Wpływ zginania na prace ciernych złaczy lukowych odrzwi ŁP przy obciqżeniach statycznych $i$ dynamicznych, praca doktorska, GIG, Katowice, 2001.

[5] SKRZYŃSKI K., Analiza wplywu rozpór i oktadzin na stateczność przestrzenna stalowej obudowy odrzwiowej, praca doktorska, GIG, Katowice, 1996.

[6] SzMELTER J., Metody komputerowe w mechanice, PWN, Warszawa, 1980.

[7] TAYLOR J.R., Mechanika klasyczna, T. 1, Wydawnictwo Naukowe PWN, Warszawa, 2006.

[8] Zienkiewicz O.C., TAYlor R.C., The Finite Element Method, Butterworth-Heinemann, London, 2000 . 